\section{OPEN JOURNAL SYSTEMS}

ISSN:2237-2202
Available on line at Directory of Open Access Journals

Journal of Hyperspectral Remote Sensing v.9, n.5 (2019) 269-282

www.periodicos.ufpe.br/revistas/jhrs

\section{Journal of Hyperspectral Remote Sensing}

www.ufpe.br/jhrs

\title{
Agricultural productivity of cassava under the rainfall of Pajeú river basin
}

\author{
Caio C. F. Diaz ${ }^{*}$ Rodrigo de Q. Miranda ${ }^{* *}$, Ranyére S. Nóbrega ${ }^{* * *}$ \\ "Doutorando da Universidade Federal de Pernambuco (UFPE), Recife-PE, Brasil. E-mail: caio.cesarwow@ hotmail.com (autor \\ correspondente) \\ ***Doutor Pesquisador CAPES/FACEPE do Programa de Pós-Graduação em Desenvolvimento e Meio Ambiente, Recife-PE, Brasil. \\ E-mail: rodrigo.qmiranda@gmail.com \\ **** Professor pesquisador da UFPE, Recife-PE, Brasil. E-mail: ranyere.nobrega@ yahoo.com \\ Received 21 August 2019; accepted 31 October 2019
}

\begin{abstract}
The crop, joined with livestock, are the most important activities in semiarid of Pernambuco and the rural activities developed in semiarid, in majority, are made by dry crops, so this kind of activity is highly dependent of rainfall that occur in the region. The main aim of this research was assess cassava productivity in function of rainfall in Pajeu river basin. Were used to this research, statistical methods applied to fill gaps of rainfall data and to model yearly cassava agricultural productivity. In general, at least 4 of 7 stations obtained good statistical relationship between the variables recording $r$ between 0.505 and 0.723 . Cassava productivity has better relationship with rainfall in center of basin between january and march and north center of basin between april and june. Figured out spatial variabilities in the rainfall influence over cassava productivity. The rainfall and productivity presented patterns with different levels of definitions over time and figured out that the potential of predictability of the agricultural productivity using rainfall to the adopted standards in the researches was satisfied, however, with some errors that can be relevant to the quality of the forecasting until 13 years.
\end{abstract}

Keywords: agroclimatology, statistic, forecast.

\section{Prudutividade agrícola da mandioca em função da precipitação pluviométrica na bacia hidrográfica do rio Pajeú}

\section{Resumo}

A agricultura, juntamente com a pecuária, são as atividades mais importantes do sertão pernambucano e a maioria das atividades agrícolas desenvolvidas no semiárido é feita em sequeiro sendo, portanto, esse tipo de atividade altamente dependente da precipitação que ocorre na região. O objetivo principal deste trabalho foi, portanto, avaliar a produtividade da mandioca em função da precipitação na bacia hidrográfica do rio Pajeú. Foram utilizados métodos estatísticos aplicados a produtividade agrícola anual de mandioca, tais como regressão linear, correlação e estatísticas de avaliação de erro. De maneira geral, ao menos quatro dos sete municípios obtiveram boa relação estatística entre as variáveis registrando $r$ entre 0.505 e 0.723 . A produtividade da mandioca correlaciona-se melhor com a precipitação no centro da bacia, entre janeiro e março e no centro norte da bacia entre abril e junho. Percebeu-se variabilidades espaciais na influência da precipitação sobre a produtividade da mandioca. A precipitação e produtividade apresentaram padrões com diferentes níveis de definição ao longo do tempo, e percebeu-se que o potencial de previsibilidade da produtividade agrícola usando a precipitação para os padrões adotados na pesquisa foi satisfatório, porém, com alguns erros que podem ser vitais para a qualidade de previsão para até 13 anos.

Palavras-chave: Agroclimatologia, estatística, previsão.

\section{Introdução}

As adversidades no clima podem ser causadas por mudanças antropogênicas ou naturais. As alterações climáticas de origem antropogênica no meio físico e, de um modo geral, podem ser irreversíveis e apresentam escala variando de pequena até a mesoescala. Quanto às alterações de origem natural, estas podem variar sua extensão da meso à grande escala e estão relacionadas com a circulação geral da atmosfera (enchentes, secas, etc.), além de estarem associadas com eventos climáticos extremos (Ferreira, 2005). 
Dentre as variáveis que compõem o clima na terra, a que apresenta maior vínculo com o ser humano, de fato, é a precipitação, uma vez que a mesma não se apresenta de forma contínua e onipresente no globo, e o homem demanda fortemente dela (Molion e Bernardo, 2002).

A variabilidade da precipitação constitui-se como um fator climático primordial para o gerenciamento e manutenção das atividades agrícolas, de forma que qualquer perturbação de ordem anômala possa afetar o regime natural das chuvas. Seja ela em qualquer escala (desde mensal até multidecadal), a precipitação tem grande importância para a agricultura, ainda que hoje em dia, a tecnologia tenha avançado de forma a amenizar tais impactos. As consequências de situações meteorológicas adversas levam constantemente a graves impactos sociais, acarretando prejuízos econômicos significativos que podem ser difíceis de serem quantificados. Tanto o clima, como o tempo afetam qualquer região e mesmo nas áreas mais preparadas, com maior disponibilidade de mecanismos tecnológicos é capaz de produzir enormes danos econômicos.

As lavouras temporárias são amplamente difundidas no Nordeste brasileiro e quando não submetidas a um eficiente sistema de irrigação sofrem forte influência da variabilidade climática. Ferreira et al. (2008) afirmam que a escassez de chuva durante longos períodos do ano e a distribuição irregular das precipitações pluviais faz parte do cenário climático do Nordeste brasileiro, resultando em risco da atividade agrícola, associado a dificuldades de plantio em épocas adequadas.

No caso do Nordeste, a associação da escassez de chuva como fator natural para problemas de produção agrícola é mais frequente do que o excesso atrelado a intensidade de um evento agudo de precipitação. Esse déficit de chuvas no Nordeste, quando intensificado, é facilmente associado a eventos de anomalias climáticas. Kayano e Andreoli (2009) apontam que as variações interanuais de precipitação no Nordeste brasileiro têm, em associação, anomalias de outros elementos meteorológicos na região e em outras regiões do globo, relacionados a sistemas dinâmicos da circulação atmosférica e entre estes, o El Niño-Oscilação Sul (ENOS) é apontado como um dos principais fenômenos responsáveis por tais flutuações.

Estudos prévios têm identificado relações entre a variabilidade da precipitação sobre o Nordeste brasileiro com eventos de ENOS, variação da temperatura da superfície do mar no oceano Atlântico, mudança nos ventos e na pressão ao nível do mar, na posição da ZCIT (Zona de Convergência Intertropical) sobre o oceano Atlântico e as frentes frias (Uvo et al., 1998). De forma conjuntural, a dinâmica atmosférica atrelada aos eventos anômalos de variação térmica identificados nos oceanos pacífico e atlântico, ajudam a perfilar o cenário agrícola na região do semiárido, sobretudo na área de estudo em questão, a bacia do rio Pajeú.

Segundo dados do IBGE do ano 2000, a mandioca é uma cultura de origem brasileira, cultivada em todo país, destacando-se no Nordeste como a maior região produtora com uma média, no período de 1994 a 1998, de 49,3\% da área cultivada e 38,9\% da produção segundo. A tolerância a seca e a solos com baixa fertilidade e ácidos, tem permitido o seu cultivo em regiões de baixa precipitação, desde que o solo apresente boa drenagem, textura arenosa ou arenoargilosa, profundidade superior a 1 metro e ausência de salinidade. Apesar da elevada tolerância a seca, a cultura possui elevado potencial produtivo, que permite aproveitar melhor os eventuais períodos de chuvas abundantes (Cavalcanti, 2000).

A bacia do Pajeu foi selecionada, pois possui umas das melhores redes de postos pluviométricos para se testar os modelos para o estudo proposto, dentro do semiárido pernambucano e a cultura da mandioca foi escolhida por seu plantio ser bastante difundido na área da bacia, detendo dados espacialmente consistentes. Diante da argumentação exposta, essa pesquisa tem como objetivo, analisar espacialmente a produtividade agrícola da mandioca na bacia hidrográfica do rio Pajeú em função da variabilidade pluviométrica e avaliar o potencial de previsibilidade agrícola da mandioca através de um modelo linear.

\section{Material e métodos}

\section{Área de estudo e dados utilizados}

A bacia do rio Pajeú (Figura 1), é a maior do Estado de Pernambuco, com uma área de $16.685 \mathrm{~km}^{2}$, que corresponde a 16,97\% da área do Estado. A área de drenagem da bacia envolve 27 municípios dos quais sete possuem suas sedes inseridas na bacia (Carnaíba, Carnaubeira da Penha, Floresta, Iguaraci, Itacuruba, Mirandiba e São José do Belmonte). Os municípios totalmente inseridos na bacia são: Afogados da Ingazeira, Betânia, Brejinho, Calumbi, Flores, Ingazeira, Itapetim, Quixabá, Santa Cruz da Baixa Verde, Santa Terezinha, São José do Egito, Serra Talhada, Solidão, Tabira, Triunfo e Tuparetama (APAC, 2010). O clima predominante na área da bacia é o BSh segundo a classificação climática de KöppenGeiger (Alvares et al., 2013), caracterizado por um clima semiárido quente com chuvas de primavera- 
verão, porém em alguns trechos de brejo de altitude, onde a umidade é mais alta devido a diminuição das taxas de evaporação proporcionada por temperaturas mais amenas e o favorecimento da formação de chuvas orográficas, o clima muda e essas áreas são classificadas como tropicais úmidas e semiúmidas. Os municípios de Triunfo e Santa Cruz da Baixa Verde, por exemplo, possuem clima com período chuvoso também durante a primavera-verão, porém com totais anuais bem mais elevados que as regiões circundantes. Segundo Assis (2016), na área do submédio São Francisco, onde o Pajeú se insere, os totais pluviométricos podem oscilar entre 300 a $1200 \mathrm{~mm}$ como os maiores valores atingindo o Alto Pajeú, enquanto que os menores acumulados anuais se encontram nas áreas próximas ao Rio São Francisco, onde, por conseguinte, a semiaridez é bem acentuada.

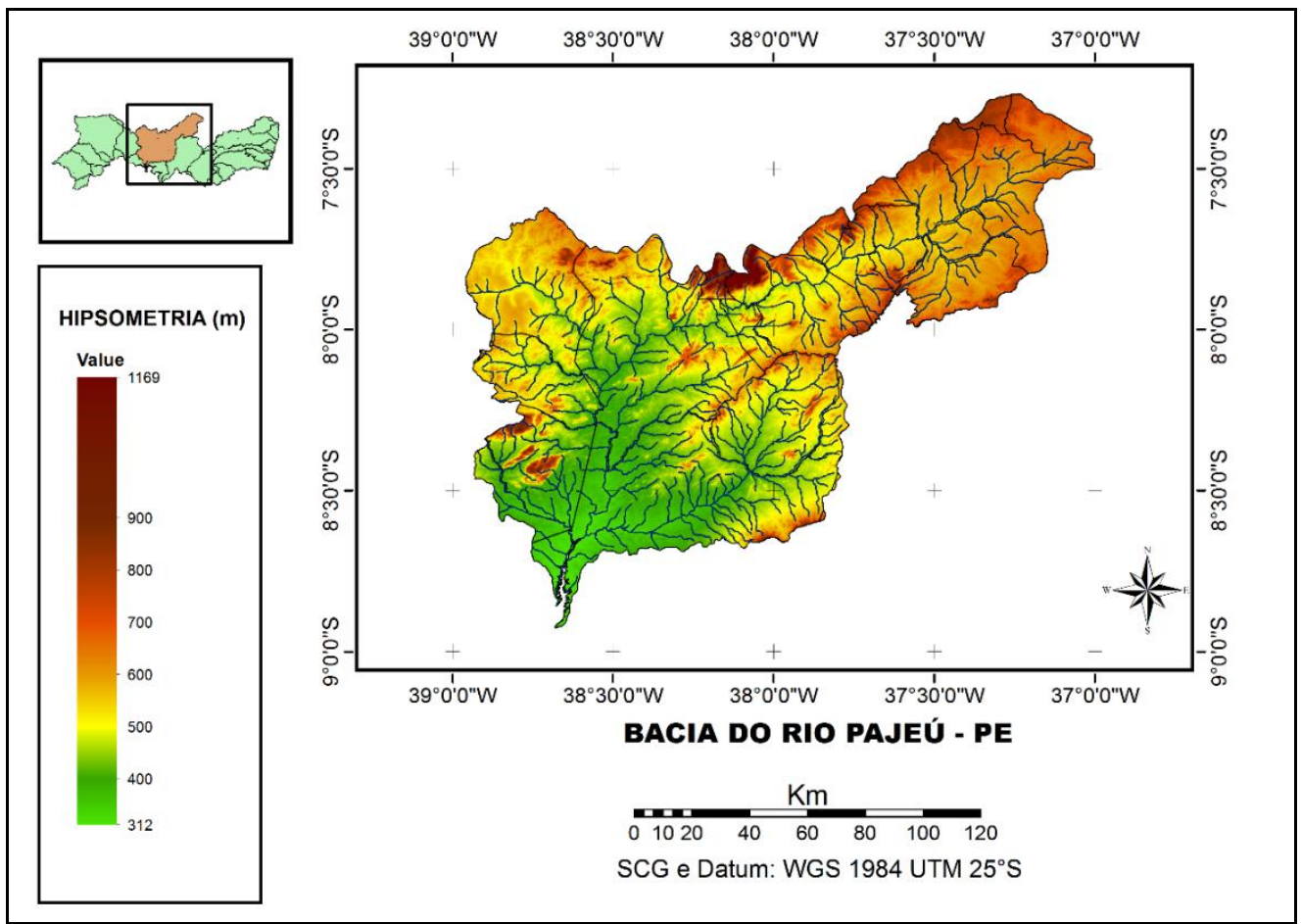

Figura 1 - Localização e hipsometria da bacia do rio Pajeú. Fonte: ZAPE Geodados/CNPM EMBRAPA, 2001.

Para a execução da pesquisa, foram utilizados dados mensais de precipitação observada entre 1994 e 2017 de sete municípios inseridos na bacia hidrográfica do rio Pajeú, são eles: Afogados da Ingazeira, Betânia, Flores, Itapetim, São José do Belmonte, Serra Talhada e Triunfo. Tais dados foram obtidos da Agência Pernambucana de Águas e Clima (APAC). Em algumas séries, havia dados faltantes, exigindo-se a utilização de preenchimento de falhas, onde para tal procedimento, viu-se a necessidade do uso de dados de outros municípios oriundos da Fundação Cearense de Meteorologia (FUNCEME), da Agência Executiva de Gestão das Águas do Estado da Paraíba (AESA) e da própria APAC. Também foram utilizados dados anuais de rendimento médio (ton/ha ${ }^{-1}$ ) da cultura de mandioca também de 1994 a 2017 dos sete municípios estudados. Tais dados são oriundos do censo agropecuário municipal que pode ser acessado através do Sistema IBGE de Recuperação Automática (SIDRA), no endereço eletrônico do Instituto Brasileiro de Geografia e Estatística. Os dados de rendimento médio foram analisados estatisticamente junto aos dados de precipitação.

\section{Metodologia aplicada}

Antes da realização das análises, foi necessário aplicar um método de preenchimento de falhas de precipitação nos municípios de Betânia, Itapetim e São José do Belmonte. Os primeiros anos da série em estudo estavam com algumas ausências de dados nessas localidades, portanto, foi selecionado o método de preenchimento de falhas por interpolação, a ponderação regional. Constitui-se de um cálculo simples, onde seleciona-se postos pluviométricos próximos e o mais equidistantes possíveis daquele posto que se quer preencher. Além desta exigência, é importante que os postos interpolados estejam na mesma região ecoclimática como é proposto em Leivas 
et al. (2006), porém não há problema disso ocorrer, pois o posto pluviométrico com falhas pode estar inserido em área de transição ecoclimática. A ponderação regional é retratada em alguns trabalhos (Pruski et al., 2004; Leivas et al., 2006; Oliveira et al., 2010).

O cálculo da ponderação regional é expresso na Eq. 1:

$$
\hat{p}=\sum\left(\frac{\bar{p}}{\bar{P}_{i}} x_{i}\right) / N_{p}
$$

Em que $\widehat{\boldsymbol{p}}$ é o valor a ser estimado, $\overline{\boldsymbol{p}}$ é a média da precipitação do posto com falhas, $\overline{\boldsymbol{P}}_{\boldsymbol{i}}$ é a média de cada posto próximo ao posto com falhas, $\boldsymbol{x}_{\boldsymbol{i}}$ é a precipitação do posto próximo no mês i, e $\boldsymbol{N}_{P}$ é o número de postos próximos ao posto com falhas que estão sendo utilizados.

No Nordeste os produtores de mandioca recebem assistência governamental para a sua produção. O objetivo deste trabalho, no entanto, é trabalhar a influência da precipitação sobre a produtividade dessas culturas minimizando a atuação de incentivos agrícolas e programas rurais. Enquanto que outras culturas são cultivadas em sequeiro no semiárido, os dados de produtividade da mandioca precisariam de um ajuste para a retirada das influencias técnicas exercidas nelas. Tal técnica faz com que os dados de rendimento agrícola se tornem modelados.

Sendo assim, optou-se pela aplicação da regressão linear para efetuar tal ajuste e gerar a partir dos dados brutos de produtividade, dados simulados de mandioca (que aqui serão chamados de dados corrigidos). O uso desta técnica estatística foi proposto por Ferreira (2005), que a usou para minimizar as tendências tecnológicas de produtividade do milho e da soja na região Sul e Sudeste. No caso do semiárido essas tendências são respaldadas por Cuenca e Mandarino (2006) e Lichtemberg e Lichtemberg (2011) para mandioca, onde ambos revelam que houve em Pernambuco nos últimos anos, aumento da produtividade nessa cultura. Portanto, o modelo de regressão foi aplicado segundo Ferreira (2005) utilizando a seguinte etapa: utilizou-se o ano como variável independente, para retirar o efeito das tecnologias adotadas nos sistemas de produção (no caso, os investimentos feitos pelo estado e pela própria iniciativa privada com maquinário, adubos, pesticidas e irrigação). $\mathrm{O}$ cálculo utilizado para isso é descrito na Eq. 2:

$$
Y c i=Y i-Y(x i)+Y(x o)
$$

Onde $\boldsymbol{Y} \boldsymbol{c i}$ é a produtividade simulada do ano "i”, $\boldsymbol{Y} \boldsymbol{i}$ é a produtividade original do ano "i", $\boldsymbol{Y}(\boldsymbol{x} \boldsymbol{i})$ é a produtividade do ano i estimado pelo modelo de regressão e $\boldsymbol{Y}(\boldsymbol{x} \boldsymbol{o})$ é a produtividade do primeiro ano da série histórica de produtividade estimada pelo modelo de regressão. Um fluxograma também foi elaborado para auxiliar a compreensão desta etapa na Figura 2.

O método estatístico da correlação linear também foi utilizado para analisar a influência da variabilidade pluviométrica na produtividade agrícola das culturas estudadas. Entretanto, neste método, não existe uma relação de variável condicionante e variável condicionada, mas tanto a precipitação quanto a produtividade são variáveis independentes. Durante o processo, a precipitação foi dividida sazonalmente (em trimestres) centradas nos meses de fevereiro (JFM) e maio (AMJ), observando apenas os dois trimestres mais chuvosos.

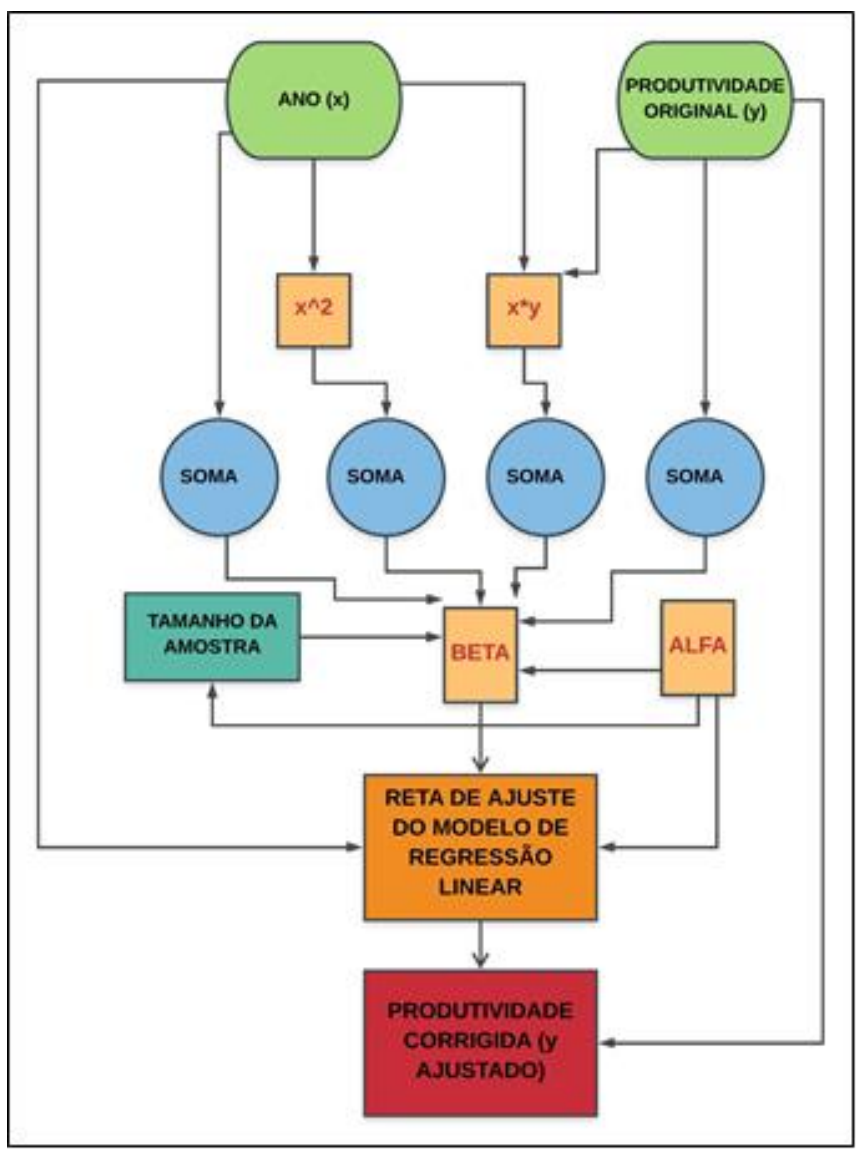

Figura 2 - Fluxograma do cálculo de correção da produtividade utilizando o modelo de regressão linear. 
Após isso foi calculado a significância estatística da correlação através do teste de hipóteses $t$ student que segundo Ferreira (2005) e Oliveira (2008) é aplicado para variáveis independentes com um número pequeno de amostras, ou seja, $<30$ e onde o número de tratamentos não ultrapasse 4. Para este teste optou-se por um nível de significância de $95 \%$ e $99 \%$ assim como foi na regressão linear. Por meio deste teste, podemos constatar se as correlações foram estatisticamente significantes e altamente significantes e qual foi o período trimestral mais bem correlacionado com a produtividade de cada cultura. Auxiliar a isso, foi utilizado também os valores críticos dos níveis de significância aplicados ao valor de $r$ que são de $0.404 \mathrm{e}$ 0.515 para o tamanho da amostra $\mathrm{n}$ que no caso corresponde ao número de anos estudados (24). A Eq. 3 a seguir descreve o teste $t$-student como:

$$
t=\frac{r \sqrt{n-2}}{\sqrt{1-r^{2}}}
$$

Em que $\boldsymbol{t}$ é o valor tabelado, $\boldsymbol{r}$ é o coeficiente de correlação da variáveis $\mathrm{X}$ e $\mathrm{Y}, \boldsymbol{n}$ é o número de amostras e $\boldsymbol{n}$-2 é o grau de liberdade do teste.

Para investigar o potencial de previsibilidade da precipitação sobre a produtividade agrícola da mandioca, foram separados, os períodos trimestrais chuvosos mais bem correlacionados com a produtividade entre os municípios que foram compreendidos como os meses de JFM ou AMJ dependendo do município. Para a execução do teste, foi aplicado a metodologia de Ferreira (2005), porém mais simplificada e adaptada para este estudo que consiste na separação da série histórica de precipitação e produtividade compreendida entre 1994 e 2017 em dois períodos. No primeiro período entre 1994 e 2004 (11 anos), foi aplicado uma regressão linear com a precipitação como variável condicionante e através da reta de ajuste, juntamente com a equação $\alpha+\beta x$, onde " $\alpha$ " representa o ponto onde a reta de ajuste toca no eixo de $y$, " $\beta$ " representa o ângulo de inclinação da reta $\mathrm{e}$ " $\mathrm{x}$ " representa os dados trimestrais se precipitação, foram gerados dados previstos de produtividade que representam o segundo período de estudo compreendido entre 2005 e 2017.

Em posse das duas séries de dados de produtividade agrícola no período de 2005 a 2017, foram utilizados testes estatísticos com o objetivo de se conhecer o grau de erro e capacidade de previsão do modelo aplicado, bem como constatar se há tendência de aumento ou diminuição da produtividade. Os testes usados foram a Raiz do Erro Médio Quadrático (REMQ), Erro Médio Absoluto (EMA) e Tendência (TEND), descritos nas equações 4,5 e 6 respectivamente:

$$
\begin{aligned}
R E M Q & =\sqrt{\sum_{y=2005}^{2014} \frac{(P d y p-P d y o)^{2}}{n}} \\
E M A & =\frac{\sum_{y=2005}^{2014}|P d y p-P d y o|}{n}
\end{aligned}
$$

$$
T E N D=\frac{\sum_{y=2005}^{2014}(P d y p-P d y o)}{n}
$$

onde $\boldsymbol{y}$ é o ano onde a previsão começa, $\boldsymbol{n}$ é o número de anos compreendidos, $\boldsymbol{P} \boldsymbol{d} \boldsymbol{y} \boldsymbol{p}$ é a produtividade prevista pelo modelo no ano y e Pdyo é a produtividade observada (aquela que foi corrigida com base nos anos) no ano $y$. $R E M Q$ é a raiz quadrada da média das diferenças individuais quadráticas entre a previsão e as observações. EMA é a média das diferenças dos valores absolutos entre previsão e a observação de um campo particular e a tendência (TEND) mede a tendência do modelo para avaliar uma variável (Ferreira, 2015). REMQ e EMA são índices equivalentes e são usados em conjunto para que ambos respaldem o grau de erro dos modelos. A correlação de Pearson também foi aplicada com o mesmo objetivo de se mensurar o caráter potencial do modelo.

\section{Resultados e discussão}

Tomando-se como ponto de partida a correção da produtividade de mandioca, podemos constatar nos gráficos das Figuras 3 e 4 que, apesar da importância dada a cultura da mandioca, a mesma apresenta queda na produção a partir de 2012 até a retomada do crescimento em 2016. Mesmo assim, os dados corrigidos se mostrariam bem dispares em relação aos dados originais. Estes valores mostram que a diferença entre tais dados depende decisivamente do grau de angulação da reta de ajuste ou beta, ou seja, quanto maior o valor de beta (para mais ou menos) maior será a diferença no ajuste do modelo. Neste caso, alguns municípios apresentaram forte tendência, com valor de 
beta alcançando quase -100 , aumentando a diferença entre os dados originais e os dados ajustados. Com relação aos cinco municípios com maior tendência negativa (beta $>0$ ), Triunfo obteve a maior correção para os dados de mandioca onde a produtividade original em 2017 foi de $8000 \mathrm{~kg} / \mathrm{ha}^{-1}$ e a corrigida foi de $5750 \mathrm{~kg} / \mathrm{ha}^{-1}$, mais de $2200 \mathrm{~kg} / \mathrm{ha}^{-1}$ de diferença. Este valor está ligado ao valor de angulação beta estar bem baixo (menor que -90), o que indica tendência negativa. Os municípios de Itapetim e São José do Belmonte também adquiriram expressiva diferença entre os dados, onde o primeiro atingiu em 2017 produtividade de $6000 \mathrm{~kg} / \mathrm{ha}^{-1}$ com correção para 3842 $\mathrm{kg} / \mathrm{ha}^{-1}$ e o segundo obteve produtividade de 10.000 $\mathrm{kg} / \mathrm{ha}^{-1}$ com correção de $8267 \mathrm{~kg} / \mathrm{ha}^{-1}$. Flores apresentou correção em 2017 de quase $21 \%$ a partir dos dados originais e Afogados da Ingazeira, como também apresentou menor tendência, teve correção do último ano da série ${ }^{1}$ abaixo de $17 \%$.

Tendência ainda menor e mais próxima a 0 foi obtida em Betânia e Serra Talhada. Sobre o primeiro, a produtividade original em 2017 foi de $7500 \mathrm{~kg} / \mathrm{ha}^{-1}$, enquanto a produtividade corrigida foi de $6220 \mathrm{~kg} / \mathrm{ha}^{-1}$. Como é possível perceber, a maior diferença entre os dados ocorre no último ano e em Betânia essa diferença se mostrou bem menor aos demais com diferença menor que $10 \%$. Levando isto para o campo das suposições é como se ao longo dos anos não tivesse havido mudanças relevantes no município ao ponto de haver melhorias visíveis nas lavouras de mandioca no período de 24 anos. O mesmo vale para Serra Talhada, porém agora com maior diferença chegando próximo a $800 \mathrm{~kg} / \mathrm{ha}^{-1}$ em 2017 (8000 kg/ha ${ }^{-1}$ nos dados originais e $7204 \mathrm{~kg} / \mathrm{ha}^{-1}$ nos dados corrigidos), mostrando também maior visibilidade no gráfico. Essas diferenças, porém, tenderiam a mudar se o tamanho da série histórica também mudasse. Logo cada município poderia apresentar realidades diferentes a exposta aqui. Portanto entende-se que na série de 24 anos, este é o cenário encontrado.

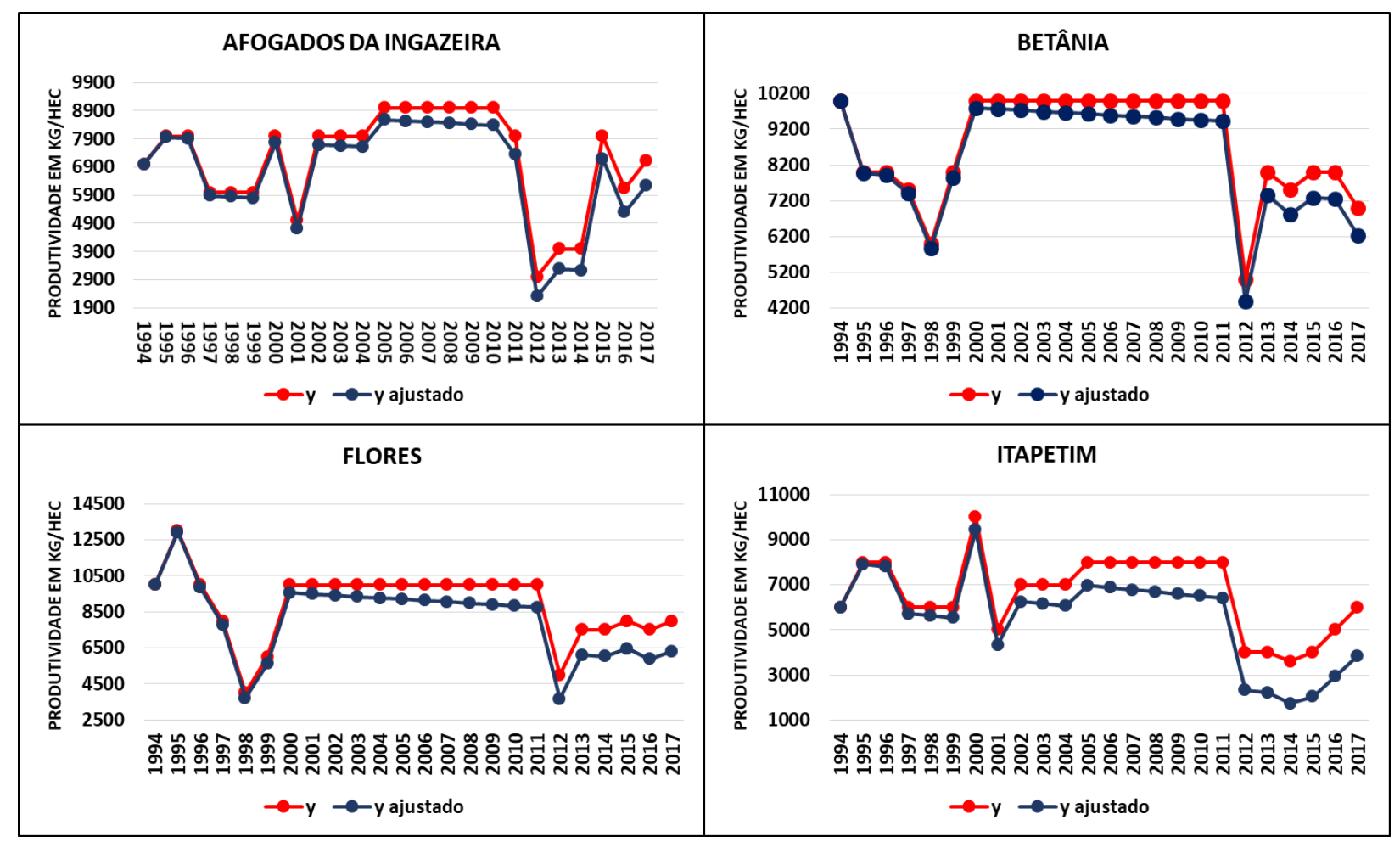

Figura 3 - Valores de produtividade agrícola normal (y) e ajustada ao modelo (y ajustado) para Afogados da Ingazeira, Betânia, Flores e Itapetim, Pernambuco. 


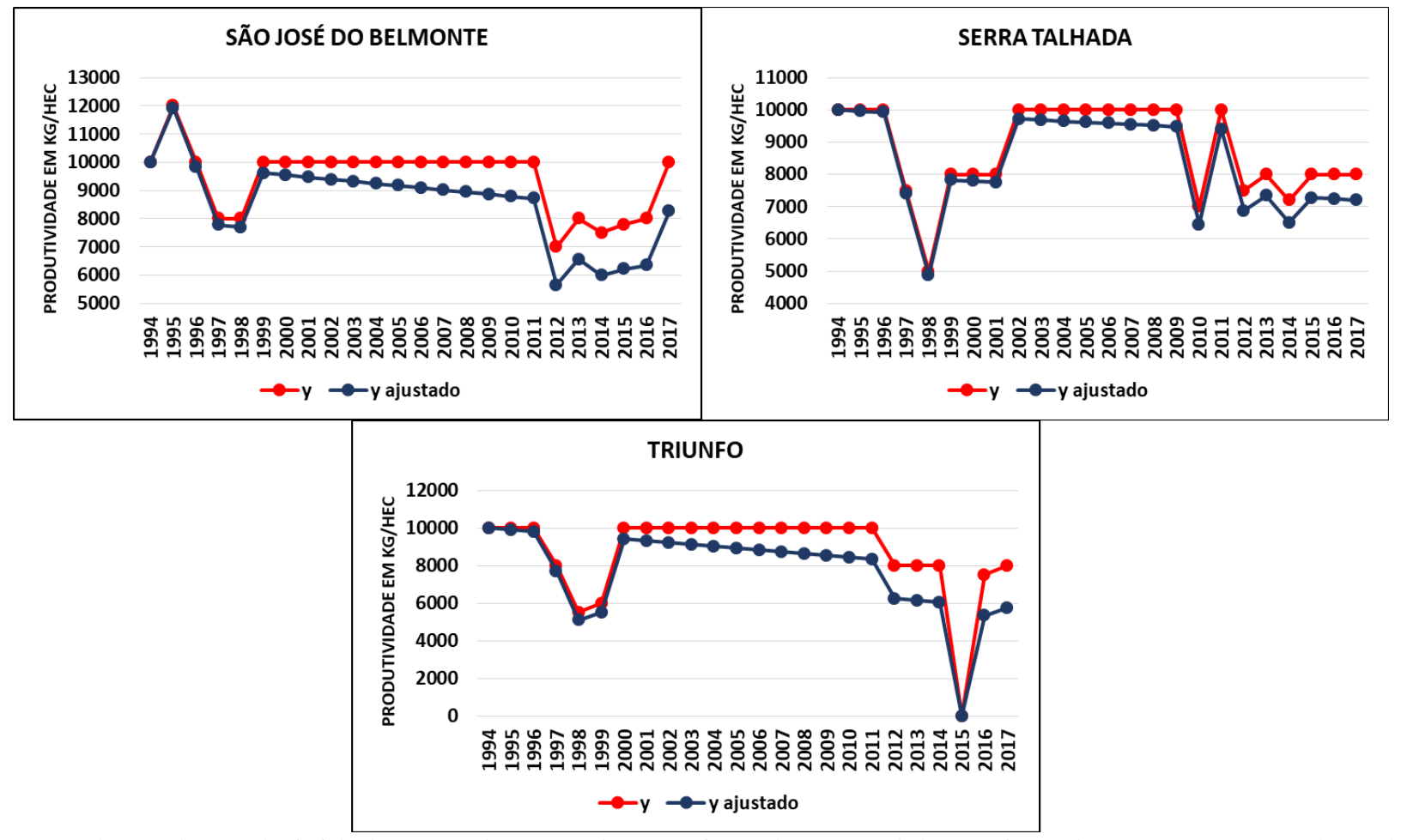

Figura 4 - Valores de produtividade agrícola normal (y) e ajustada ao modelo (y ajustado) para São José do Belmonte, Serra Talhada e Triunfo, Pernambuco.

Sobre as análises de correlação, observa-se na Figura 5, dois mapas A e B da bacia do Pajeú correspondendo dois trimestres chuvosos (janeiro, fevereiro e março em A e abril, maio e junho em B). O primeiro possui representação em uma grande área com significância estatística desde o Sul, passando pelo Norte até as fronteiras de Flores (a Leste) e São José do Belmonte (A Oeste). O segundo possui significância estatística alta centrada no médio Pajeú, em Afogados da Ingazeira, porém com área menor de significância que o mapa representando o primeiro trimestre chuvoso.

Percebe-se no mapa que a terceira classe de cima para baixo representa o limite do intervalo de cinfiança de $95 \%$, enquanto que a primeira classe de cima para baixo, denotando os maiores valores de correlação compreende o intervalo de confiança de 99\%, mostrando como grande parte da bacia nos meses de JFM apresenta boa relação estatística entre as variáveis. Nesta classe, encontram-se os municípios de Betânia e Serra Talhada no mapa A, este último apresenta índices acima da média para o $r$. Neste caso em específico para os dois municípios, os níveis de produtividade acompanham os índices de chuva, melhor que os demais municípios, o que garantem os valores de alta significância para estas localidades. Já no mapa B, destacam-se os municípios de Afogados da Ingazeira e Flores, o primeiro com altíssima significância estatística entre a produtividade e o segundo trimestre chuvoso. Talvez por serem municípios mais altos e estarem mais deslocados a norte, recebem maior influência da Zona de Convergência Inter Tropical (ZCIT) e da orografia em intensidade e volume.

No entanto, nota-se que os demais municípios, apesar de não obterem significância estatística, chegaram muito próximo disso (Tabela 1) e, portanto, mostram indícios estatísticos satisfatórios para se relacionar espacialmente a produtividade agrícola da mandioca com a variabilidade pluviométrica nessas áreas.

Analisando a tabela, constata-se uma diversidade nos valores dos coeficientes de correlação, desde valores de correlação mais próximas de 0 , valores muito próximos ao mínimo para significância estatística, até valores positivos que extrapolam o valor crítico de alta significância. Destarte, percebe-se uma boa quantidade de valores com boa significância estatística e da mesma forma, uma relevante quantidade de valores sem significância estatística, comprovando a variabilidade espacial do índice. É de vital importância enfatizar que o período chuvoso que mais bem correlacionou com produtividade de mandioca foi entre janeiro e março, coincidindo com a época de plantio das sementes, seguindo de brotamento das manivas e crescimento do sistema radicular e coincidindo também 
com o crescimento das plantas em estágio adulto no ano seguinte, uma vez que a lavoura de mandioca pode durar mais um ano.

Silva et al. (2008), obtiveram resultados interessantes ao relacionar a produtividade agrícola com a precipitação no interior de São Paulo. Eles mostram que para a cana de açúcar, por exemplo, as correlações foram bem próximas a zero e justificam este valor ao afirmar que a cultura canavieira e alicerçada ao agronegócio. Por outro lado, nas culturas de soja e milho, eles obtiveram boas correlações, considerando 17 anos como o tamanho da amostra, com 0.46 e 0.47 , respectivamente. $\mathrm{O}$ primeiro caso mostra como os insumos agrícolas utilizados para a produção podem interferir a análise. Já os outros dois resultados são bem semelhantes aos encontrados aqui, ainda que clima e culturas, sejam diferentes. Ferreira (2005) também obteve valores diversos de correlação entre a produtividade de soja e milho para os estados do Sul e Sudeste do Brasil, sendo os trimestres de dezembro, janeiro e fevereiro (DJF) e janeiro, fevereiro e março (JFM), os períodos com os maiores valores variando entre 0.16 e 0.63 .

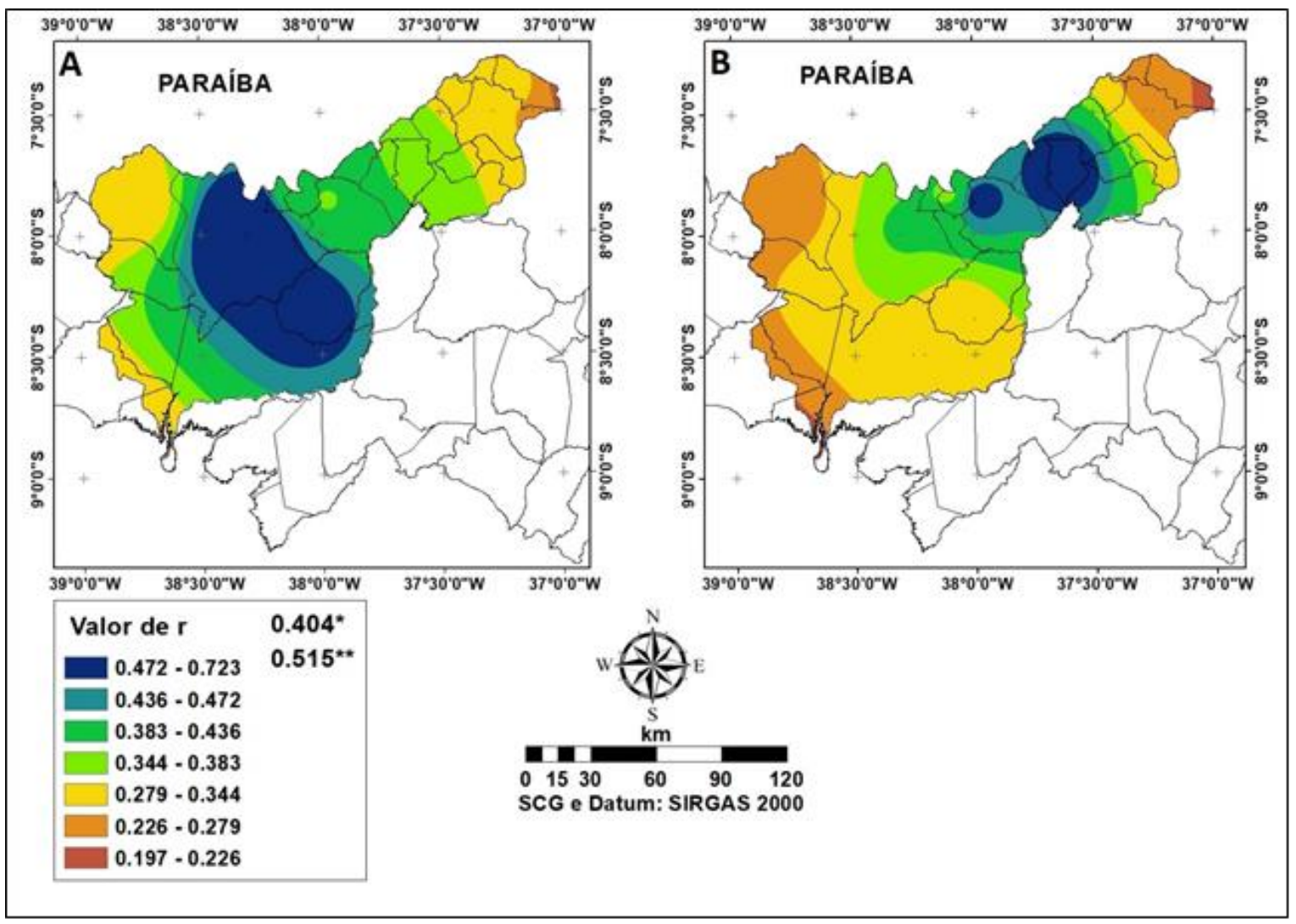

Figura 5 - Coeficiente de correlação $r$ entre a produtividade agrícola da mandioca e a precipitação trimestral de janeiro, fevereiro e março (A) e abril, maio e junho (B).

Tabela 1 - Valores dos coeficientes de correlação $r$ e os valores críticos para 95 e $99 \%$ de significância estatística.

\begin{tabular}{lcc}
\hline Municípios & $\boldsymbol{r}(\mathbf{J F M})$ & $\boldsymbol{r}(\mathbf{A M J})$ \\
\hline Afogados da Ingazeira & 0,382 & 0,541 \\
Betânia & 0,523 & 0,311 \\
Flores & 0,379 & 0,505 \\
Itapetim & 0,292 & 0,245 \\
São José do Belmonte & 0,291 & 0,244 \\
Serra Talhada & 0,723 & 0,392 \\
Triunfo & 0,386 & 0,374 \\
\hline critical value $(95 \%)$ & 0,404 & 0,404 \\
\hline critical value $(99 \%)$ & 0,515 & 0,515 \\
\hline
\end{tabular}


O potencial de previsibilidade para a cultura da mandioca com base no trimestre chuvoso mais bem correlacionado, foi efetuado separando a série de 24 anos de estudo em duas séries, uma de 11 anos e uma de 13 anos. O modelo de regressão foi então, aplicado a primeira série e o resultado foi comparado com a segunda série através da raiz do erro médio quadrático, erro médio absoluto e tendência utilizando a soma dos erros médio e as correlações.

O modelo adotado para esta análise foi importante, pois mostrou como a produtividade da mandioca se comportaria se a mesma estivesse totalmente em função da variabilidade trimestral da precipitação. $\mathrm{O}$ resultado do modelo é mostrado nas Figuras 6 e 7, com a série de produtividade estimada pelo modelo e a produtividade observada de sete municípios entre os anos de 2005 a 2017.

Constata-se que as estimativas, de uma maneira geral tendem a ter valores mais estáveis que os valores observados de produtividade. No final da série, quando a produtividade observada cai drasticamente na maioria dos municípios, a produtividade estimada se mantém com valores equivalentes ao dos anos anteriores. Importante destacar como até 2010, os valores estimados de produtividade estão quase sempre acima dos valores observados até o ano de 2011, onde ambas as variáveis, em quatro municípios, praticamente parelham-se, ocorrendo então uma ruptura de tendência, face os valores observados que sofrem uma queda no ano seguinte devido à seca severa que atingiu o NE.

Mesmo em municípios como Afogados da Ingazeira, Flores e Itapetim, que obtiveram totais pluviométricos abaixo de $100 \mathrm{~mm}$ em 2012 e 2013, apresentaram estimativas acima dos valores observados. Já outros municípios com pluviometria trimestral abaixo da média nesses dois anos, como Serra Talhada, Triunfo e Betânia, mostraram maior instabilidade e patamares estimados equivalentes, dos valores de produtividade observada. Em Serra Talhada por exemplo, em 2013 choveu $131 \mathrm{~mm}$ entre janeiro e março e a estimativa de produtividade com base nesse dado foi de $6835 \mathrm{~kg} / \mathrm{ha}^{-1}$ contra $7342 \mathrm{~kg} / \mathrm{ha}^{-1}$ da produtividade observada, sendo o único município apresentando este fenômeno para o ano referido.

No primeiro caso em que o valor estimado está bem acima do observado é uma constatação a se questionar, pois em casos que a precipitação mal chega a $50 \mathrm{~mm}$, as estimativas em cima disso serem maiores que a observação não parece condizer bem com a realidade, portanto, neste caso o modelo apresenta uma falha, entretanto nos exemplos inversos, o modelo de estimativa parece obter êxito em seus resultados. Infelizmente, a pesquisa de Ferreira (2005), que dá base a esta, não expôs os dados encontrados por ela a partir desta ótica. Por isto, não há como discutir uma analogia entre os resultados encontrados nos dois trabalhos.

Após os primeiros anos de seca, porém, alguns municípios revelam uma leve recuperação de safra nos anos seguintes, enquanto que o modelo se mantêm estável. No entanto vale destacar o comportamento das variáveis nos dois últimos anos em Afogados da Ingazeira, Betânia e Flores onde o modelo acompanha a ascendência observada da safra de mandioca. Vale frizar também que se optou por não incluir Triunfo no ano de 2015, uma vez que naquele ano não houve safra e sua inclusão prejudicaria análise do modelo para o referido município.

REMQ e EMA são ferramentas importantes para se mensurar o grau de erro entre dados estimados e originais (observados) de uma mesma variável. Geralmente por sua própria natureza estatística, a REMQ apresenta valor maior que a EMA como é observado nos resultados de Pereira et al. (2008) e Cunha e Martins (2004), entretanto há casos em que os valores das duas estatísticas ficam muito próximo. Este acontecimento indica que os valores estimados acompanham quase que paralelamente os valores originais ou uma das variáveis possuem valores sempre acima ou abaixo dos valores concorrentes da outra variável e quando os valores das estatísticas estão distantes uma da outra indica o contrário, ou seja, não há um acompanhamento entre os valores.

A Figura 8 mostra os valores de REMQ e EMA para a produtividade de mandioca nos sete municípios em estudo. Os menores valores de erro indicam maior aproximação e precisão da produtividade estimada com relação aos valores de produtividade originais. Dentre estes, destacam-se Betânia e Serra Talhada que além dos baixos valores de erro, também apresentam maior aproximação entre si, indicando com veemência que o modelo foi mais preciso para a produtividade destes municípios. 


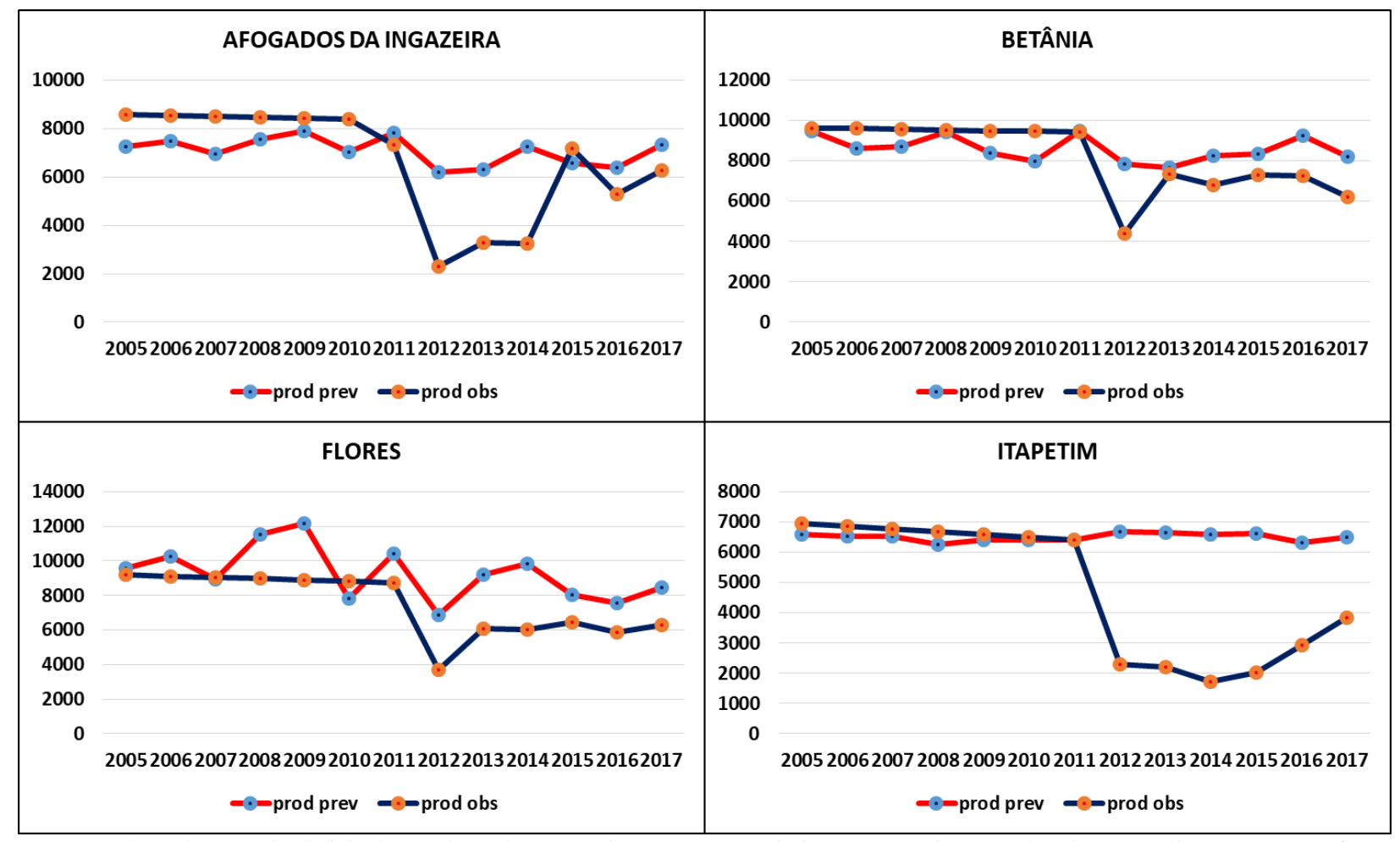

Figura 6 - Dados de produtividade estimada com base na precipitação e observada de mandioca para Afogados da Ingazeira, Betânia, Flores e Itapetim, Pernambuco.

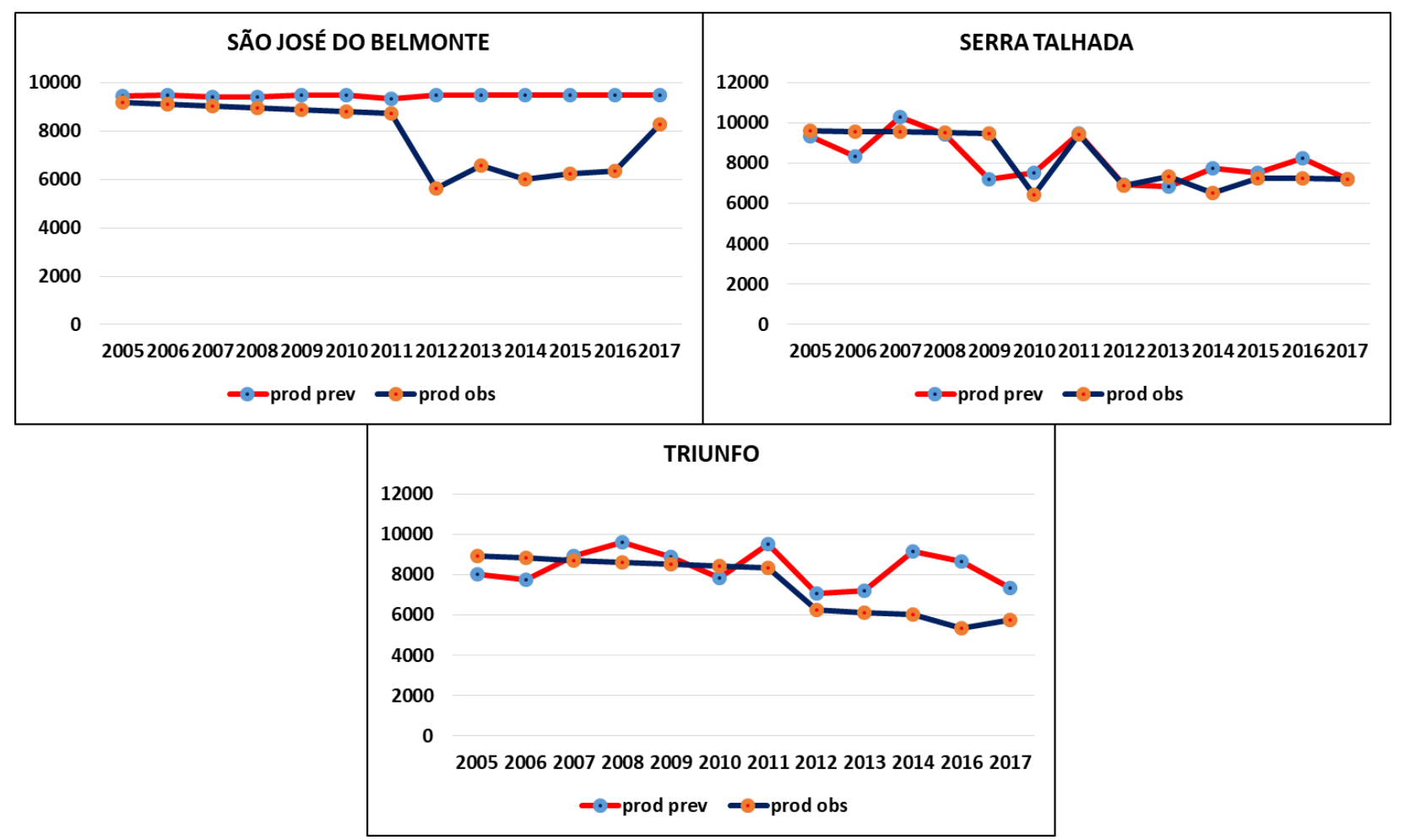

Figura 7 - Dados de produtividade estimada com base na precipitação e observada de mandioca para São José do Belmonte e Triunfo, Pernambuco. 


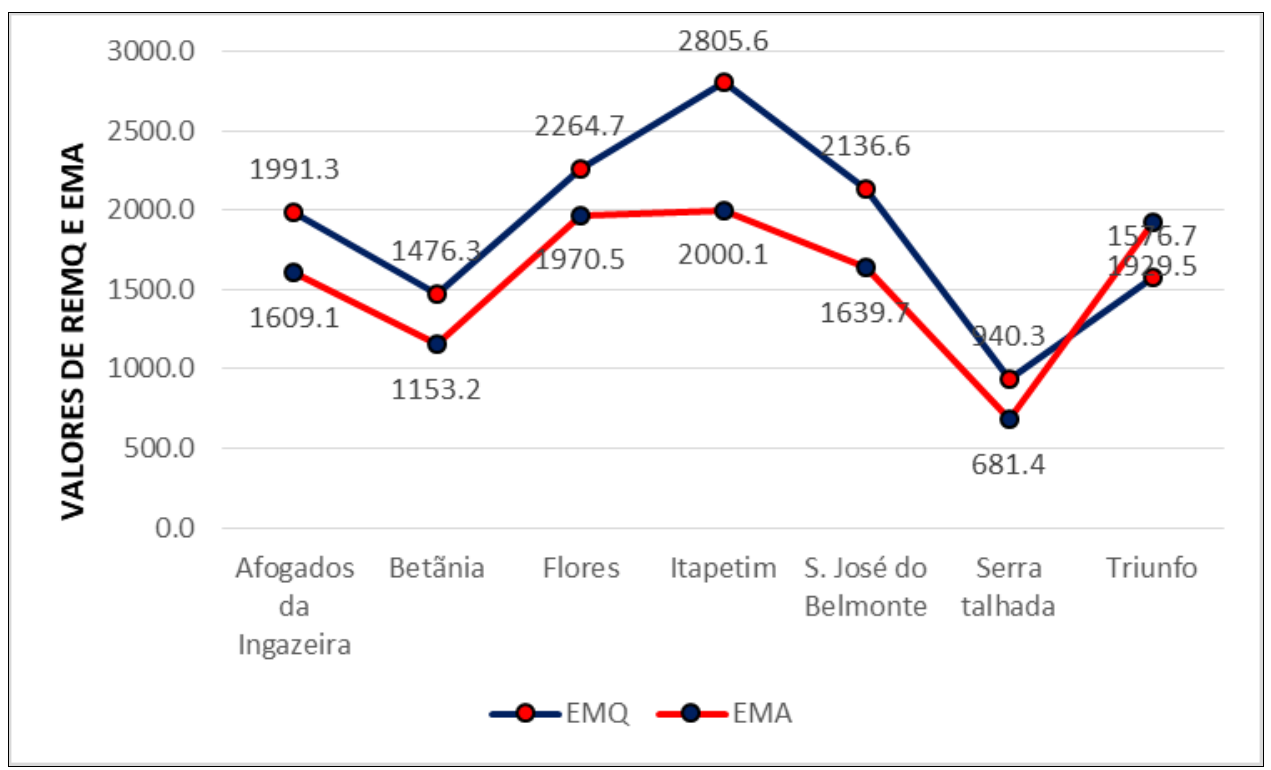

Figura 8 - Precisão da previsão de produtividade da mandioca utilizando raiz do erro médio quadrático e erro médio absoluto.

Serra Talhada, em especial, obteve REMQ abaixo de $1000 \mathrm{~kg} / \mathrm{ha}^{-1}$, sendo que a diferença entre REMQ e EMA foi de apenas $259 \mathrm{~kg} / \mathrm{ha}^{-1}$. O grau dos erros para Serra Talhada, de certa maneira ainda é alto considerando o valor médio original da produtividade da mandioca, porém é inegavelmente menor e com precisão melhor que nos demais municípios. A exemplo de oposição, temos Flores e Itapetim. No primeiro, temos grande diferença e altos valores de erro médio quadrático e absoluto, anunciando emparelhamento pouco aparente e menor proximidade entre os valores estimados e originais. Itapetim vai além com diferença entre REMQ e EMA ainda maior e valores absolutos maiores que em Flores. A diferença entre os erros quadrático e absoluto e Itapetim chegou a quase $32 \%$, diferente de Flores, que apesar dos altos valores de erro, apresentou a menor \% diferencial entre os índices, com apenas 13\%. São José do Belmonte também logrou de expressivos valores nos índices.

Estes valores indicam menor precisão do modelo para estimar a produtividade da mandioca nestes municípios, porém é preciso destacar a evidente causa para a discrepância desses valores, calcada nos anos de 2012 a 2015 da série onde a diferença entre a produtividade estimada e observada cresceu com a manutenção das estimativas e queda da produtividade nos últimos anos. Se não fosse por isso e o modelo tivesse estimado forte queda junto aos valores originais, os resultados para REMQ e EMA provavelmente teriam sido bem menores e próximos.
Ferreira (2005), trabalhando com este tipo de método para a soja no Rio Grande do Sul, porém variando o número de amostras, obteve erros bem menores, porém com uma grande diferenciação entre os valores desses erros. Com $\mathrm{n}=10$ o valor de REMQ pairava entre 50 e $100 \mathrm{~kg} / \mathrm{ha}^{-1}$, enquanto que o EMA estava próximo dos $300 \mathrm{~kg} / \mathrm{ha}^{-1}$. A diferença entre as duas estatísticas no trabalho da autora reflete o porquê da correlação também a $n=10$ estar abaixo de 0,200, apesar dos valores absolutos serem bem baixos.

A análise de tendência da produtividade da mandioca nada mais é que um somatório dos erros médios com o propósito de se estabelecer um prognóstico futuro para a produtividade com base no comportamento produtivo de anos anteriores. Essa tendência, dependendo do comportamento da produtividade em cada município pode ser negativa ou positiva ou ainda pode nem haver uma tendência efetiva. Esta análise, porém, diz respeito a tendência estabelecida sob os aspectos da produtividade estimada pelo modelo de regressão em relação com a produtividade observada.

A Figura 9 mostra o nível de tendência de produtividade estimada de mandioca para os sete municípios em estudo. Todos os municípios manifestaram possibilidade de ascendência na produtividade em anos futuros, ou seja, tendência positiva não havendo cenários apresentando possibilidade de queda de rendimento agrícola em anos futuros, ou seja, tendência negativa. 
O caso mais proeminente de tendência positiva foi para Flores com ascendência maior que 1800 $\mathrm{kg} / \mathrm{hec}$, enquanto a menor tendência ficou por conta de Serra Talhada com $5,4 \mathrm{~kg} / \mathrm{ha}^{-1}$, ou seja, praticamente esboça manutenção do cenário produtivo. Esse resultado entra de encontro com o que ocorre com os dados originais, uma vez que os últimos anos de produtividade observada da série, deslocariam a linha de tendência para a maioria dos municípios para baixo. Isso mostra como o caráter mais estável das estimativas revela resultados dispares em relação a produtividade observada, mas também é um indício de que a precipitação como fator que determina prognóstico da produtividade pode revelar um cenário diferenciado em relação a realidade.

A maioria dos municípios apresentou, portanto, tendência de produtividade positiva, indicando que as precipitações do trimestre mais bem correlacionado como variável determinante, apontam majoritariamente para a ascendência no rendimento agrícola da mandioca. No caso do trabalho de Ferreira (2005), observou-se o mesmo resultado para a soja no Estado de RS com 10 anos de prognóstico, ou seja, tendência positiva. Entretanto, a medida que o número de anos estimados (número da amostra) era aumentado, essa tendência diminuía, se tornava negativa e assim se mantinha. Acontece, no entanto, que a autora constatou aumento na imprecisão da estimativa a medida que os anos eram aumentados, portanto, há uma possibilidade de que no Pajeú o mesmo fenômeno estatístico ocorresse. Infelizmente nos moldes atuais no que concerne a disponibilidade de dados, a constatação desta afirmação ainda é inviável a nível municipal.

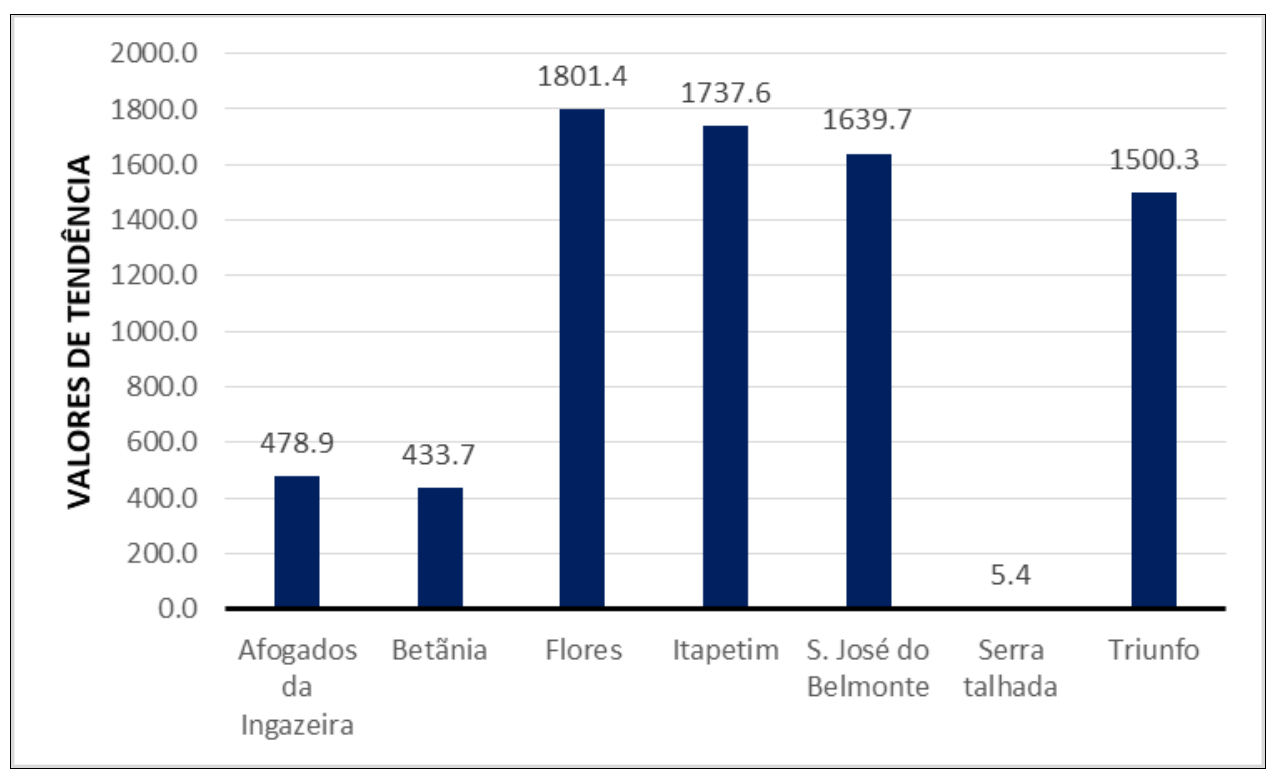

Figura 9 - Dados de tendência para a produtividade estimada da mandioca.

Com os dados de correlação, foi possível na análise identificar em quais municípios a produtividade estimada tinha relação estatística com a produtividade original. Desta forma seria possível concluir uma série de constatações a despeito do nível de qualidade das previsões efetuadas pelo modelo de regressão adotado. Os resultados encontrados atingiram até certo ponto as expectativas, porém não estão isentos de críticas.

$\mathrm{Na}$ Figura 10, observamos boas correlações onde dos sete grupos de amostras, três ultrapassaram o valor crítico mínimo (representado pela linha verde para + e para -) e uma amostra conseguiu atingir valor crítico de alta significância estatística. Mesmo os municípios que não atingiram o valor crítico, apresentou boas correlações. Cinco grupos de amostras obtiveram correlações positivas, enquanto dois atingiram correlações negativas. Sobre essas últimas, raciocina-se que a produtividade estimada se orientou de forma contrária a produtividade original, ou seja, quando uma tendeu a ser positiva, a outra tendeu a ser negativa.

Leva-se em consideração que as correlações positivas indicam características de comportamento similares entre a produtividade estimada e observada, principalmente nos municípios que atingiram o valor crítico, entretanto isso não é bem verdade. De fato, nos casos de Betânia, Serra Talhada e Triunfo, as estimativas estiveram bem próximas das observações, entretanto isto não ocorre em Afogados da Ingazeira e em menor grau, em Flores. Os últimos anos da série 
foram substancialmente relevantes para abaixar o valor da correlação, mas não o bastante para fazer com que Afogados da Ingazeira não apresentasse um dos maiores valores de correlação da análise. Mesmo
Triunfo aparentando possuir melhores relações entre as estimativas e as observações, obteve somente o pior valor de correlação.

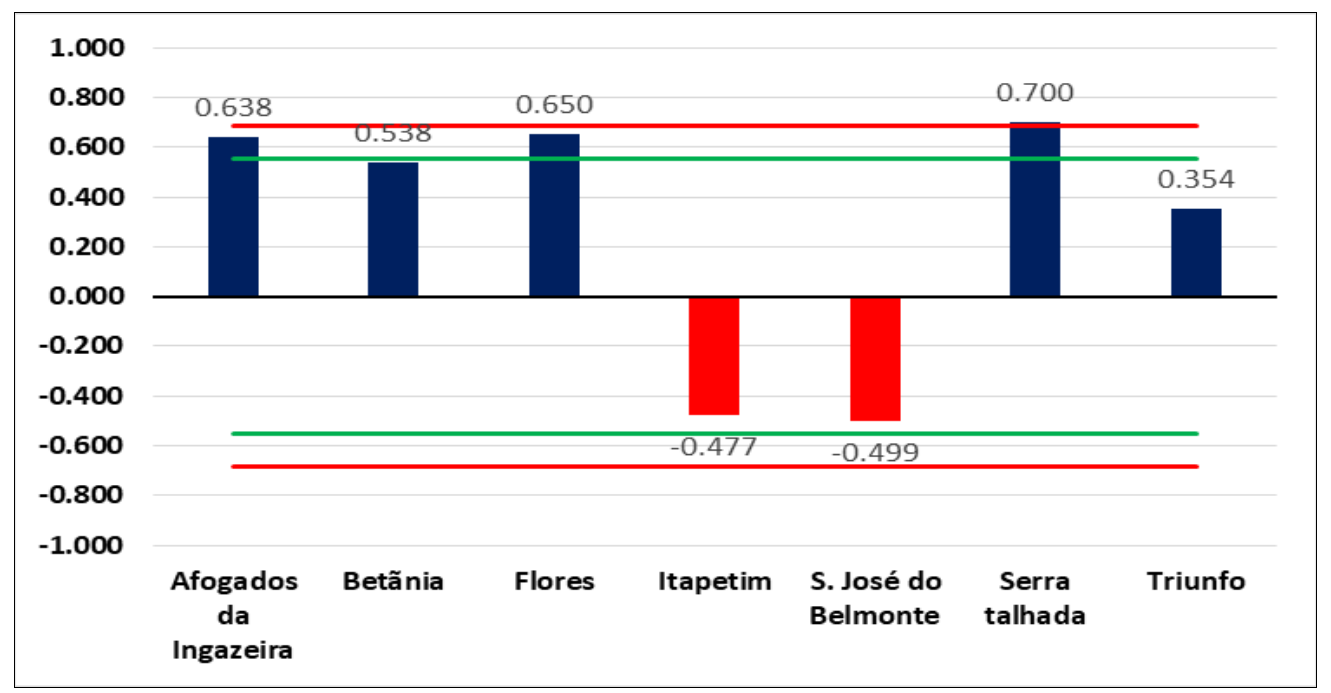

Figura 10 - Correlações entre a produtividade estimada e observada de mandioca para os anos de 2005 a 2017.

Acontece que o coeficiente de correlação pode indicar também se os pares de dados estão em consonância, mesmo que tais pares representem dados de mesma natureza, porém com disparidade entre os valores absolutos. Isto quer dizer que com a oscilação mútua de valores entre os pares, o valor do coeficiente aumenta e se torna alto. Se o valor dos pares oscilarem, sem haver acréscimo de diferença nos pares seguintes, na mesma orientação ou em orientações contrárias (relação negativa), o coeficiente "linear" tende a aumentar. Foi o que fez Flores e Serra Talhada obterem as maiores correlações da análise, mesmo que os valores de Triunfo estivessem mais próximos.

Regionalmente, não existe uma lógica por trás dos valores de correlação. Flores, Afogados e Triunfo são municípios limítrofes que apresentaram valores distintos. O mesmo ocorre entre São José do Belmonte e Serra Talhada. Mesmo assim em se tratando da relevância deste resultado para o modelo, pode-se dizer que tais valores de correlação geraram um ponto de positividade para o modelo de previsão empírica para a produtividade da mandioca. Em outras palavras, os valores estimados de produtividade da mandioca apresentam, no geral, boa relação com os valores observados. Este resultado, portanto, acaba sendo validado pela assertiva de Ferreira (2005) quando ela indaga que o modelo adotado é válido para se gerar previsões de até 11 anos, fato constatado e corroborado nesta pesquisa, uma vez que foram utilizados 13 anos de previsão e bons resultados.

\section{Conclusões}

O modelo de regressão linear para ajustar dados originais de produtividade agrícola se mostrou eficaz para a produtividade de mandioca. Recomendase então que se use este modelo para ajustar dados de culturas irrigadas, já que as modificações pretendidas com o uso deste modelo para este tipo de cultura parecem ser mais incisivas e evidentes. O coeficiente de correlação linear usado para achar relações entre a precipitação e a produtividade agrícola obteve expressivo êxito dando a pesquisa, claros indícios estatísticos de que a precipitação de forma isolada pode influenciar na produtividade e desenvolvimento da cultura de mandioca. A precipitação, portanto, em escala trimestral parece desempenhar papel relevante no desempenho das culturas, porém com o desenrolar da pesquisa, fica evidente como sozinha, a variabilidade pluviométrica não dá conta de explicar todos os fenômenos. Ainda assim, fica visível como o período chuvoso, bem como a concentração de chuva entre os trimestres deste período, é de vital importância para o êxito na produção agrícola na bacia do rio Pajeú.

$\mathrm{O}$ modelo de regressão mostrou certo grau de êxito quando aplicado como teste de previsão empírica de produtividade da mandioca. Os resultados se encontraram de maneira estatisticamente satisfatória, com bons patamares para a análise de tendência e correlação, mostrando que para prognósticos, o modelo pode ser usado para previsões de até 13 anos, 
entretanto, ao mesmo tempo mostrou erros grosseiros quanto a disparidade dos dados estimados com os observados nos anos finais da série e erros relevantes entre os dados em alguns municípios.

\section{Agradecimentos}

À Universidade Federal de Pernambuco, ao Departamento de Ciências Geográficas e a Fundação de Amparo a Pesquisa de Pernambuco (FACEPE), que fomentaram o desenvolvimento da pesquisa, seja com insumos financeiros, espaço ou ferramentas.

\section{Referências}

APAC. Agência Pernambucana de Águas e Clima, 2019. Monitoramento pluviométrico. Disponível: http://www.apac.pe.gov.br/meteorologia/monitoram ento-pluvio.php. Acesso: 15 maio 2019.

Alvares, C.A., Stape, J.L., Sentelhas, P.C., Gonçalves, J.L.M., Spavorek, G., 2013. Köppen's climate classification map for Brazil. Meteorologische Zeitschrift 22, 711-728.

Assis, J.M.O., 2016. Variabilidade do clima e cenários futuros de mudanças climáticas no trecho do submédio da bacia hidrográfica do rio São Francisco. Tese (Doutorado). Recife, UFPE.

Cavalcanti, J., 2000. Mandioca no semi-árido. Embrapa semi-árido, Petrolina. (Instruções técnicas da Embrapa semi-árido, 27).

Cuenca, M.A.G., Mandarino, D.C., 2006. Aspectos agronômicos da cultura da mandioca: características e evolução da cultura no estado de Pernambuco entre 1990 e 2004. Embrapa, Aracaju.

Cunha, A.R., Martins, D., 2004. Estudo comparativo entre elementos meteorológicos obtidos em estações meteorológicas convencional e automática em Botucatu, SP, Brasil. Revista Brasileira de Agrometeorologia 12, 103-111.

Ferreira, D.B., 2005. Relações entre a variabilidade da precipitação e a produtividade agrícola de soja e milho nas regiões Sul e Sudeste do Brasil. Dissertação (Mestrado). São José dos Campos, INPE.

Ferreira, V.M., Andrade, J.A.S., Silva, C.R., Maschio,
R., 2008. Consumo relativo de água pelo milho e pelo feijão-caupi, em sistema de cultivos solteiro e consorciado. Revista Brasileira de Agrometeorologia 16, 96-106.

Kayano, M.T., Andreoli, R., 2009. Variabilidade decenal e multidecenal, in: Cavancanti, I., Ferreira, N., Silva, M.G.J., Dias, M.A.F.S., (Eds.), Tempo e Clima no Brasil. Oficina de Textos, São Paulo, pp. 375-383.

Leivas, J.F., Berlato, M.A., Fontana, D.C., 2006. Risco de deficiência hídrica decendial na metade sul do Estado do Rio Grade do Sul. Revista Brasileira de Engenharia Agrícola e Ambiental 10, 397-407.

Lichtemberg, L.A., Lichtemberg, P.S.F., 2011. Avanços na bananicultura brasileira. Revista Brasileira de Fruticultura, volume especial, 29-36.

Molion, L.C.B., Bernardo, S.O., 2002. Uma revisão da dinâmica das chuvas no Nordeste Brasileiro. Revista Brasileira de Meteorologia 17, 1-10.

Oliveira, A.F.G., 2008. Testes estatísticos para comparação de médias. Revista Eletrônica Nutritime 5, 777-788.

Oliveira, L.F.C., Fioreze, A.P., Medeiros, A.M.M., Silva, M.A.S., 2010. Comparação de metodologias de preenchimento de falhas de séries históricas de precipitação pluvial anual. Revista Brasileira de Engenharia Agrícola e Ambiental 14, 1186-1192.

Pereira, L.M.P., Caramori, P.H., Ricce, W.S., Gaviglione, J.H., 2008. Análise comparativa de dados meteorológicos obtidos por estação convencional e automática em Londrina - PR. Seminário de ciências agrárias 29, 299-306.

Pruski, F.F., Pereira, S.B., Novaes, L.F., Silva, D.D., Ramos, M.M., 2004. Precipitação média anual e vazão específica média de longa duração, na Bacia do São Francisco. Revista Brasileira de Engenharia Agrícola e Ambiental 8, 247-253.

Silva, D.F., Prela-Pantano, A., Neto, J.L.S.A., 2008. variabilidade da precipitação e produtividade agrícola na região do médio Paranapanema, SP. Revista Brasileira de Climatologia 3 e 4, 101-116.

Uvo, C.B., Zebiak, S., Repelli, C.A., Kushnir, Y., 1998. The relationships between Tropical Pacific and Atlantic SST and Northeast Brazil monthly precipitation. Journal of climate 11, 551-562. 